\title{
BATIK ULTRAFILTRASYON MEMBRAN BİYOREAKTÖRÜ İLE GERÇEK GRİ SU ARITIMI
}

\author{
${ }^{1}$ Can ASAN (iD) , ${ }^{2 *}$ Levent GÜREL ${ }^{(D)}$, ${ }^{3}$ Hanife BÜYÜKGÜNGÖR \\ ${ }^{1}$ Dış İlişkiler Ĕ̆gitim ve Araştırma Daire Başkanlı̆̆ı, Orman Genel Müdürlüğ̈̈, Ankara, TÜRKIYYE \\ ${ }^{2}$ Çevre Mühendisliği Bölümü, Mühendislik Fakültesi, Pamukkale Üniversitesi, Denizli, TÜRKIYE \\ ${ }_{3}^{3}$ Çevre Mühendisliği Bölümü, Mühendislik Fakültesi, Ondokuz Mayıs Üniversitesi, Samsun, TüRKIYYE \\ ${ }^{1}$ canasan@ogm.gov.tr , ${ }^{2}$ lgurel@pau.edu.tr, ${ }^{3}$ hbuyukg@omu.edu.tr
}

\section{(Geliş/Received: 15.05.2018; Kabul/Accepted in Revised Form: 03.07.2019)}

ÖZ: Bu çalışma kapsamında, batık tip bir membran biyoreaktör (MBR) sistemi, gerçek ortamdan elde edilen gri suyun arıtılabilirliğini ve giderim performansını belirlemek için kullanılmıştır. Kimyasal oksijen ihtiyacı (KOI), toplam azot (TN) ve toplam fosfor (TP) gibi kirlilik parametreleri çalışmada kullanılmıştır. Bu çalışmada havalandırma tankına daldırılmış olan membran ünitesi, 0,03 $\mu \mathrm{m}$ ortalama gözenek boyutuna sahip olan bir ultrafiltrasyon modülüdür. Bu membran sistemi 140-280 mbar düzeyindeki bir transmembran basınç aralığında sürekli konfigürasyonda 25 gün boyunca işletilmiştir. Biyoreaktördeki askıda katı madde konsantrasyonu, sürekli konfigürasyondaki MBR arıtım süreci boyunca 2000-3000 mg/L aralığında değişmiştir. Bu periyottaki membran akısı, 29 ile $62 \mathrm{~L} / \mathrm{m}^{2}$.gün aralığındadır. KOİ, TN ve TP parametrelerindeki giderim verimlilikleri için ortalama değerler sırasıyla \%96, \%73 ve \%64 şeklinde tespit edilmiştir. Bu çalışmalar boyunca elde edilen sonuçlar, yönetmeliklerde yer alan ilgili standartlar ile karşılaştırılmıştır. Çıkış suyundaki KOİ konsantrasyonunun deşarj limitlerinin altında olduğu, TN ve TP konsantrasyonlarının ise deşarj limitlerinin üzerinde ancak bu değerlere yakın oldukları bulunmuştur. Ayrıca sulama amaçlı yeniden kullanım amaçlandığı takdirde, bu çalışmada incelenen parametreler doğrultusunda suyun tekrar kullanımının uygun olacağı değerlendirilmektedir.

Anahtar Kelimeler: KOI Giderimi, Membran Biyoreaktör, Besi Maddesi Giderimi, Ultrafiltrasyon Membranı

\section{Real Greywater Treatment by Using Submerged Membrane Bioreactor}

\begin{abstract}
In this study, a submerged type membrane bioreactor was used to determine the removal performance and treatability of greywaters originated from real life. The pollutant parameters such as chemical oxygen demand (COD), total nitrogen (TN) and total phosphorus (TP) concentrations were studied. The membrane unit immersed in the aeration tank was an ultrafiltration module with a mean pore size of $0.03 \mu \mathrm{m}$. This membrane system was operated for 25 days in continuous mode at a transmembrane pressure interval of 140-280 mbar. The MLSS concentration of the bioreactor was in the range of 2000-3000 mg/L during the continuous MBR treatment period. The flux of the membrane in this period was in the range of $29-62 \mathrm{~L} / \mathrm{m}^{2} \mathrm{~d}$. Average values of COD, TN and TP removal efficiencies were found to be 96,73 and $64 \%$, respectively. The results obtained in these studies were compared with discharge standards in legislations. Effluent COD concentration was below the discharge limits, while $\mathrm{TN}$ and TP concentrations were high but close to the limit values. In addition, if reuse of treated wastewater for irrigation is aimed, it is considered that the reuse of wastewater will be appropriate in the direction of parameters examined in this study.
\end{abstract}

Key Words: COD Removal, Membrane Bioreactor, Nutrient Removal, Ultrafiltration Membrane 


\section{GİRIŞ (INTRODUCTION)}

Günümüzde su kıtlığı önemli bir konu olarak tartışılmakta olup, musluklardan akan sular oldukça değerli görülmektedir. Fakat musluk sularını günlük hijyen amaçlı olarak kullanmak bir zorunluluktur. Atıksuların yeniden kullanımı için geri çevrimi, su ihtiyacının yönetimi açısından iyi bir strateji olarak görünmektedir. Bu yolla, çevredeki kirleticiler en aza indirilebilir ve yüksek kaliteli sular korunmuş olur (Al-Jayyousi, 2003). Bu yüzden, kullanım sonrası bu suları geri kazanmak için ileri arıtma teknolojilerinin kullanılması önemli bir hal almıştır.

Gri suyu ifade etmek için birçok tanım bulunmaktadır. Genellikle, bu tip atıksular tuvaletlerden oluşan atıklarla temasta olmayan evsel atıksular olarak tanımlanabilir. Buna ek olarak, bulaşık makinelerinden ve mutfak lavabolarından kaynaklanan atıksular gri sulara dâhil edilmemektedir. Gri sularda, deri, saç, vücut yağları, diş macunu, şampuanlar, sabunlar, vücut bakım ürünleri, tıraş sonrası atık materyaller, köpük, beyazlatıcılar, azot, fosfor, yüzey aktif maddeler, yağ ve gres, bulanıklık, askıda katılar, bakteriler vb. çeşitli birçok madde bulunabilmektedir (Ghaitidak ve Yadav, 2013).

Merkezi olmayan yaklaşıma göre, arıtma tesisleriyle merkezi atıksu yönetimi oldukça pahalı bir prosestir. Çünkü bazı şehirlerde evlerden merkezi arıtma sistemlerine olan boru hattı mesafeleri oldukça uzun olabilmektedir. Bazen, boru hatlarının inşası ve bakım maliyetleri arıtma tesislerinden daha yüksek düzeylere çıkabilmektedir. Bu yaklaşımla, yerleşim bölgelerinden ortaya çıkan gri sular diğer atıksulardan kaynakta ayrılmakta, toplanmakta, arıtılmakta ve bahçe sulaması, tuvalet gider suyu ve diğer temizlik işlemleri gibi amaçlarla tekrar kullanılmaktadır (Abdel-Kader, 2013; Eriksson ve diğ., 2009; Liu ve diğ., 2010).

Sulama ve diğer açık alanda kullanma amaçları dikkate alınmadığı takdirde, sadece gelişmiş ülkelerdeki konutlarda kullanılan su miktarları kişi başına 100 ile 180 L/gün aralığında bulunmaktadır. Bu miktarlar toplam kentsel su tüketiminin \%30-70'ine eşit olmaktadır. Atıksuların \%60-70'i tuvaletler hariç gri su kategorisine girmektedir (Friedler ve Hadari, 2006). Evlerdeki tüm su kullanımının büyük bir bölümünü, \%33 ve \%18 oranlarıyla, sırasıyla duşlar ve çamaşır makineleri oluşturmaktadır (KujawaRoeleveld ve Zeeman, 2006). Bu yüzdeler toplam gelen suyla karşılaştırıldığında oldukça yüksek gözükmektedir. Bu durum gri suların değerlendirilmesinin önemini ortaya koymaktadır.

Gri sulardan kirleticilerin giderimi için kullanılabilecek çeşitli arıtma prosesleri bulunmaktadır. Gri su arıtımında, çeşitli fiziksel, kimyasal ve biyolojik prosesler kullanılmaktadır (Li ve diğ., 2009). Fiziksel arıtım kategorisinde, dezenfeksiyon prosesi ile birlikte kaba toprak, kum ve diğer filtrasyon prosesleri (Katukiza ve diğ., 2014; Zuma ve diğg., 2009) ve hatta membran filtrasyonu (Boddu ve diğ., 2016) kullanılmaktadır. İyon değiştirme(Nawaz ve Sengupta, 2017), foto-katalitik oksidasyon (Sanchez ve diğ., 2010) ve koagülasyon (Friedler ve diğ., 2008) gibi kimyasal arıtım metotları aynı zamanda gri sulara da uygulanmaktadır (Li ve diğ., 2009). Gri suyun geri çevrimi için bu fiziksel ve kimyasal arıtma teknolojilerinin yanı sıra biyolojik prosesler bazı uygulama alanlarına sahip olabilmektedir. Bu biyolojik yöntemlerden bazıları dönen biyolojik kontaktör sistemleri (Abdel-Kader, 2013), anaerobik çamur örtü sistemleri (Elmitwalli ve Otterpohl, 2007), yapay sulak alanlar(Arunbabu ve diğg., 2015; Wurochekke ve diğ., 2014), ve membran biyoreaktörlerdir (Bani-Melhem ve diğ., 2015; Merz ve diğ., 2007).

Membran biyoreaktörler (MBR) biyolojik prosesler ile membran teknolojisini birleştiren biyolojik arıtım sistemleridir (Judd, 2008). Bu sistemlerde, membran filtrasyonunun bir sonucu olarak son çöktürme havuzlarına, kum filtrasyonuna (Melin ve diğ., 2006) ve aynı zamanda dezenfeksiyon uygulamalarına (Lv ve diğ., 2006) ihtiyaç bulunmamaktadır. MBR sistemleri sızıntı sularının, evsel ve endüstriyel atıksuların arıtımı için kullanılabilmektedir. Aynı zamanda su ıslahı ve tekrar kullanım membran teknolojisi sayesinde başarılı bir şekilde gerçekleştirilebilmektedir (Innocenti ve diğ., 2002). MBR proseslerinin katı madde alıkonma süresi reaktörde atıksuyun hidrolik alıkonma süresinden bağımsız olmaktadır. Böylelikle, F/M (besin/mikroorganizma) oranı en aza indirilerek biyoreaktör içinde yüksek çamur konsantrasyonları sağlanabilmektedir. Düşük F/M oranları ve yüksek çamur yaşlarında, çamur üretimi düşmektedir (Rosenberger ve diğ., 2002). Batık tip membran sistemleri enerji tüketimi 
esas alındığında daha etkili gözükmektedir. MBR sistemleri kirleticileri etkili bir şekilde giderebilmekte ve aynı zamanda da şok ve yüksek atıksu yüklerini karşılamaktadır (Guo ve diğ., 2008).

Bu çalışmada, batık tip membran biyoreaktör sistemi, gerçek ev ortamından temin edilen gerçek ölçekli gri sudan organik kirleticileri, toplam azot ve toplam fosforu gidermek amacıyla kullanılmıştır. Bu çalışmanın amacı, aerobik MBR sisteminin performansını ortaya koymak ve gri suların kullanım alanlarındaki standartların tespit edilmesine yardımcı olacak yararlı verileri elde etmektir.

\section{MATERYAL VE YÖNTEM(MATERIAL AND METHOD)}

Bu bölümde, gerçek gri suyun özellikleri, deneylerden kullanılan ekipmanlar ve deneysel işleyiş verilmiştir.

\section{Gri Suyun Özellikleri ve Analizler(Greywater Characteristics and Analyses)}

Bu çalışmada kullanılan gri sular bir evde bulunan el yıkama lavabosu ve çamaşır makinesinden ortaya çıkan atıksulardan oluşmaktadır. Bu gri sular 2 ve 3 gün aralıklarla bu kaynaklardan toplanmıştır. Reaktöre yapılacak olan besleme işleminde kullanılacak olan tank bu su ile doldurulmuştur. Bu besleme tankında, ayrıca sürekli bir şekilde havalandırma gerçekleştirilmiş olup, böylelikle yüzebilen maddelerin gri sudan ayrılması hedeflenmiştir. Havalandırma işleminin uygulandığı biyoreaktör ise bu tank vasıtasıyla beslenmiştir. Bu gri suyun özellikleri Çizelge 1'de verilmektedir. Arıtım çalışmalarında, KOİ, toplam azot ve toplam fosfor parametreleri analizleri, Merck Spectroquant Nova 60 fotometresi kullanılarak Merck marka test kitleri ile gerçekleştirilmiştir. Toplam koliform, BOİ analizleri ve askıda katı madde ölçümleri Standart Metotlar'a (APHA, 1985) göre uygulanmıştır.

Bu gri suya uygulanan KOİ ve BOİ analizleri neticesinde elde edilen sonuçlar incelendiğinde, bu değerlerin Türkiye'deki deşarj limitlerine göre oldukça yüksek olduğu Çizelge 1'den net bir şekilde görülebilmektedir. Aynı zamanda, bu atıksuyun mikrobiyolojik açıdan da yüksek konsantrasyonlarda mikroorganizma içerdiği ve tekrar kullanım için mutlak arıtılması gerekliliği söz konusudur.

Çizelge 1. Gri suyun özellikleri
Table 1. Characteristics of greywater
\begin{tabular}{|c|c|c|c|}
\hline Parametre & Min & Maks & $\begin{array}{c}\text { Deşarj limitleri } \\
\text { SKKY, 2008 }\end{array}$ \\
\hline KOİ $(\mathrm{mg} / \mathrm{L})$ & 451 & 812 & 90 \\
\hline BOİ $(\mathrm{mg} / \mathrm{L})$ & 165 & 213 & 35 \\
\hline Toplam azot $(\mathrm{mg} / \mathrm{L})$ & 60 & 68 & - \\
\hline Toplam fosfor $(\mathrm{mg} / \mathrm{L})$ & 5,0 & 7,5 & - \\
\hline Toplam koliform $(\mathrm{cfu} / 100 \mathrm{~mL})$ & $1.10^{6}$ & $5.10^{9}$ & - \\
\hline
\end{tabular}

\section{Deneysel İşleyiş̧(Experimental Process)}

Çalışmalarda 34 L hacminde bir biyoreaktör kullanılmıştır. Gri su, 25 L kapasiteli bir besleme tankından reaktöre verilmiştir. Deney biyoreaktörünün içinde kullanılan aktif çamur yerel bir atıksu arıtma tesisinden sağlanmış olup, reaktör içerisine eklendikten sonra iki hafta boyunca membran filtrasyonu uygulanmaksızın havalandırılmıştır. Bu esnada, aktif çamurdaki mikroorganizmaların atıksuya alışması maksadıyla atıksu sırasıyla \%10, 25, 50, 75 oranlarında seyreltilmek suretiyle aktif çamura eklenmiş olup seyreltme oranları üç günde bir artırılmıştır. Bu iki haftalık dönem boyunca biyoreaktör kesikli tip işletim modunda ve membran dahil edilmeden çalıştırılmıştır. Bu periyodun ardından, membran modülü biyoreaktör içerisine yerleştirilmiş ve sürekli işletim modu uygulanmaya başlanmıştır. Sürekli arıtım çalı̧̧malarında kullanılan membran modülü polisülfon materyalinden 
üretilmiş olup, $0.03 \mu \mathrm{m}$ gözenek boyutuna sahip bir ultrafiltrasyon membranıdır. Kullanılan membran modülüne ait çeşitli özellikler Çizelge 2'de sunulmaktadır.

Çizelge 2. Membran modülünün özellikleri

Table 2. Characteristics of membrane module

\begin{tabular}{|c|c|}
\hline Modül çapı $(\mathrm{m})$ & 0,1 \\
\hline Gözenek boyutu $(\mu \mathrm{m})$ & 0,03 \\
\hline Etkin uzunluk $(\mathrm{m})$ & 0,24 \\
\hline Fiber iç çapı $(\mathrm{m})$ & 0,008 \\
\hline Fiber diş çapı $(\mathrm{m})$ & 0,01 \\
\hline Bir modüldeki fiber sayısı & 32 \\
\hline Fiber yüzey alanı $(\mathrm{m} 2)$ & 0,00603 \\
\hline Bir modülün toplam yüzey alanı $(\mathrm{m} 2 /$ module $)$ & 0,193 \\
\hline
\end{tabular}

Sürekli işletim tarzı boyunca membran akısı 28,5-62,0 L/m².gün aralığında tutulmuştur. Arıtım çalışmaları boyunca düşük ve yüksek $\mathrm{pH}$ değerlerinin olumsuz etkilerinden korunabilmek için $\mathrm{pH}$ değeri 7 ile 8 civarlarında korunmuştur. Havalandırma işlemi için bir havalandırma pompası kullanılmış olup, aktif çamur prosesindeki canlı ortam için yeterli miktarda oksijen sağlamak amacıyla hava akış hızı 5-6 L/dk aralığında uygulanmıştır. Aynı zamanda havalandırma işlemi ile birlikte biyoreaktör içerisindeki biyokütle karıştırılmış ve membran yüzeyi üzerinde de birikmenin en aza indirilmeli sağlanmıştır. Membran sistemindeki transmembran basıncı (TMB), tüm arıtım işlemi boyunca 0,28 bara kadar artış göstermiştir. Membran biyoreaktör sistemi (Gürel ve Büyükgüngör, 2011) tarafından yapılan çalışmada kullanılan sistem ile benzerlik taşımakta olup, bu çalışmada kullanılan membran modülü ve deney sisteminin detaylı bir şeması Şekil 1'de gösterilmektedir. Çalışmada gerçekleştirilen ölçümlerde ön havalandırma işlemine giriş bölümünden ve membran çıkışından örnekler alınarak tüm sistemin giriş ve çıkış KOİ, toplam fosfor ve azot konsantrasyonları hesaplanarak verimler elde edilmiştir.

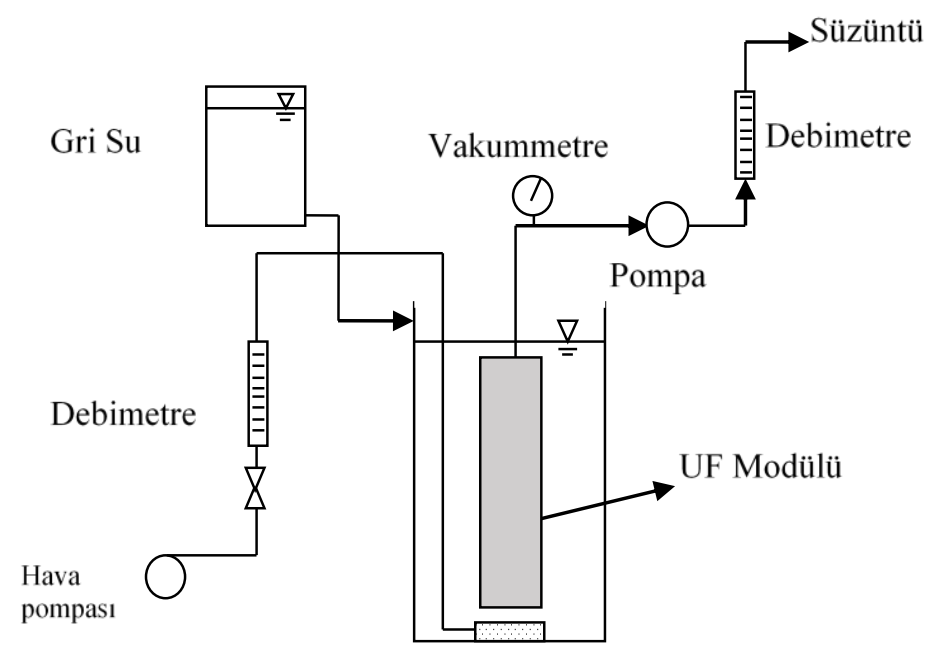

Taş difüzör

Şekil 1. UF membran sistemi

Figure 1. UF membrane system 


\section{SONUÇ ve TARTIŞMALAR(RESULTS and DISCUSSIONS)}

Bu çalışmada gerçek gri su örneğinin KOİ, toplam fosfor ve toplam azot konsantrasyonlarının bir ultrafiltrasyon membranı bulunan bir biyoreaktör kullanılarak biyolojik olarak arıtılması amaçlanmıştır. Tüm arıtım prosesi boyunca reaktördeki AKM konsantrasyonu 2000 ile 3000 mg/L arasında değişiklik göstermiştir.

\section{KOİ Arıtımı(COD Treatment)}

Biyoreaktörün KOİ konsantrasyonu, batık membran biyoreaktör sisteminin arıtım verimini ve performansını belirlemek için günlük olarak izlenmiştir. Bu biyoreaktörün hidrolik alıkonma süresi ortalama $45 \mathrm{~L} / \mathrm{m}^{2}$ gün'lük ortalama bir membran akısı için ortalama olarak 93,6 saattir. Bu değerler, gri suyun başarılı bir şekilde arıtımı için oldukça yeterli görünmektedir. Çalışılan dönem boyunca elde edilmiş olan sonuçlar Şekil 2'de gösterilmektedir.

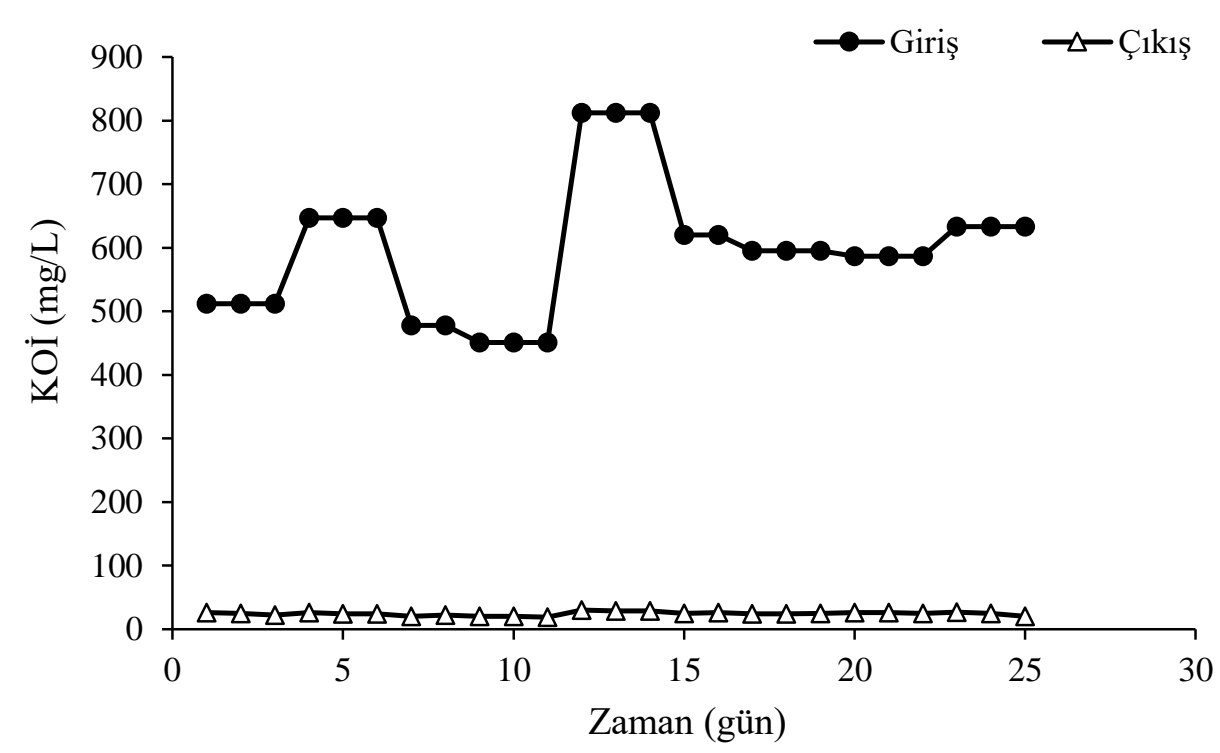

Şekil 2. Batık membran biyoreaktörle organik madde giderimi

Figure 2. Removal of organic substance by submerged membrane bioreactor

Arıtım prosesi boyunca ham gri suya ait KOİ konsantrasyonu değişiklik göstermiştir. Buna karşın, membran biyoreaktörün arıtım verimi bu gri suyun değişken organik yükünden etkilenmemiştir. Bu membran sisteminin maksimum giderim verimi \%97 olarak bulunmuştur. Giderim çalışmalarının ardından, çıkış suyuna ait minimum ve maksimum KOİ değerleri sırasıyla 19 ile $30 \mathrm{mg} / \mathrm{L}$ olarak bulunmuştur. Gri suyun başarılı bir şekilde arıtılması için en önemli unsurlardan biri atıksuyun reaktörde uzun hidrolik alıkonma süresidir. Biyoreaktör içindeki mikroorganizmalar, uzun alınkonma sürelerinde giderim verimini maksimize ederek organik maddelerin parçalanmasını sağlamışlardır. Santasmasas ve diğ., 2013 tarafından yürütülen bir çalışmada gri suları arıtmak için polietersülfon membranları kullanılmıştır. KOİ giderim veriminin \%90 değerlerine ulaştığı bulunmuştur. Aynı zamanda yapmış oldukları çalışmada elde ettikleri sonuçları Avrupa Direktifi 91/271 EEC (CEC, 1991) ile karşılaştırmışlar ve KOİ değerlerinin bu direktif tarafından belirlenmiş olan sınır değerlerin altında kaldığını saptamışlardır (Santasmasas ve diğ., 2013).

Bir başka çalışma spor ve sosyal tesislerden gri suyun arıtımı için yürütülmüştür. Söz konusu çalışmada kullanılan membran boşluklu fiber tipi bir ultrafiltrasyon membranı olup, gözenek boyutu 0,1 $\mu m^{\prime}$ dir. Sisteme uygulanmış olan maksimum transmembran basıncı 0,4 bar'dır. Arıtım işlemi neticesinde çıkış suyunda elde ettikleri minimum KOİ konsantrasyonu $15 \mathrm{mg} / \mathrm{L}$ olup, \%85 verime 
ulaşmışlardır (Merz ve diğg., 2007). Bani-Melhem ve diğ., 2015 tarafından yürütülen bir çalışmada ise gözenek boyutu 0,04 $\mu \mathrm{m}$ olan bir ultrafiltrasyon membranı kullanılarak gri su giderimi araştırılmıştır. Çalışmalarında, membran arıtım süreci boyunca ortalama olarak \%88 KOİ giderim verimi elde etmişlerdir. Ortama olarak çıkış suyunda ulaştıkları KOİ konsantrasyonu $45 \mathrm{mg} / \mathrm{L}$ olarak verilmiştir (Bani-Melhem ve diğ., 2015).

Yukarıda anılan çalışmaların ışığında, bu çalışmada ortalama olarak \%96'lık bir KOİ giderim veriminin, bu membranın gerçek gri sulardan organik maddelerin gideriminde çok başarılı olduğu sonucunu ortaya koyduğu söylenebilir. Aynı zamanda membran biyoreaktör çıkışından elde edilen arıtılmış gri suyun tekrar kullanılabilirliğine karar vermek için bir kalite karşılaştırması yapmak gerekmektedir. Tüm çalışma periyodunda çıkış suyundaki ortalama KOİ konsantrasyonu $24 \mathrm{mg} / \mathrm{L}$ olarak analiz edilmiştir. Su Kirliliği Kontrolü Yönetmeliğinde, alıcı ortama atıksuların deşarj edilebilmesi için KOİ parametresinin maksimum izin verilebilen değeri 180 mg O $2 / \mathrm{L}$ (nüfus aralığ 1 84-2000) olarak verilmektedir (SKKY, 2008). Aynı zamanda Avrupa Direktifi 91/271 EEC için, bu limit değer $125 \mathrm{mg}$ $\mathrm{O}_{2} /$ L'dir (CEC, 1991). Bu düzenlemelerin deşarj limitleri, bu çalışmada elde edilen sonuçlarla karşılaştırıldığı takdirde, arıtılmış suda analiz edilen 24 mg/L'lik KOİ konsantrasyonunun bu değerlerin oldukça altında kaldığı açık bir şekilde görülebilmektedir. Ayrıca ülkemizde atıksuların yeniden kullanımı ile ilgili yasal düzenleme (AATTUT, 2010) incelendiğinde KOİ değerine bağlı bir değerlendirme yapılmadığı, sadece BOİ değerinin ele alındığı görülmektedir. Buna bağlı olarak deney sonuçları neticesinde KOİ değerine eşdeğer olacak BOİ değerinin yönetmelik gereği $20 \mathrm{mg} / \mathrm{L}$ 'den aşağıda olacağı net bir şekilde anlaşılabilmektedir.

\section{Toplam Azot Giderimi(Removal of Total Nitrogen)}

Besi maddeleri biyolojik arıtma proseslerinde mikroorganizmalar için çok önemli besin kaynaklarıdır. Özellikle, besi maddeleri olan azot ve fosfor elementlerinin optimum bir miktarı, biyolojik arıtımın başarılı bir şekilde gerçekleşmesini temin etmek için sucul ortamda bulundurulmalıdır. Fakat bu besi maddeleri arıtılmış çıkış sularında deşarj limitlerinin altında bir seviyeye indirilmedikçe alıcı sucul ortam için çok tehlikeli bir hal almaktadır. Aerobik MBR sisteminin toplam azot giderim verimini gözlemlemek için toplam azot konsantrasyonları her gün analiz edilmiştir.

Zamana karşı giriş ve çıkış atıksuyundaki toplam azot konsantrasyonları Şekil 3'te gösterilmektedir. Gri suyun toplam azot konsantrasyonu $58-68 \mathrm{mg} / \mathrm{L}$ arasında değişim göstermiştir. Çıkış suyunda rastlanılan en düşük toplam azot konsantrasyonu tüm işletim periyodu boyunca $15 \mathrm{mg} / \mathrm{L}$ olarak tespit edilmiştir. MBR prosesinin ortalama verimi \%74 olarak bulunmuş olup, konvensiyonel aktif çamur biyoreaktörleri ile karşılaştıııldığında oldukça iyi bir değerdir. Scheumann ve Kraume 2009, batık bir membran ardışık kesikli reaktörü ile çalışmalar gerçekleştirmiştir. Yaptıkları çalışmada kullanılan membran ünitesinin gözenek boyutu $0,4 \mu m^{\prime}$ dir. Çalı̧̧malarında, ortalama çıkış toplam azot konsantrasyonunu $4,1 \mathrm{mg} / \mathrm{L}$ olarak elde etmişlerdir. Toplam azot için elde edilmiş olan giderim verimi \%76 olarak tespit edilmiştir. Çalışmalarında kullandıkları anoksik koşullar toplam azot giderim verimliliğine pozitif olarak yansımıştır (Scheumann ve Kraume, 2009).

Ma ve diğ., 2015 tarafından yürütülen bir başka çalışmada ise membran biyoreaktör ile donatılmış olan bir gri su arıtım sistemi $250 \mathrm{~m}^{3}$ lük etkili hacme sahiptir. Bu prosesle, atıksudaki toplam azot konsantrasyonu 12,3-38,7 mg/L değerlerinden 9-27 mg/L değerlerine düşürülmüş olup, sadece ortalama $\% 29^{\prime}$ luk bir arıtım verimi elde edilmiştir (Ma ve diğ., 2015). 


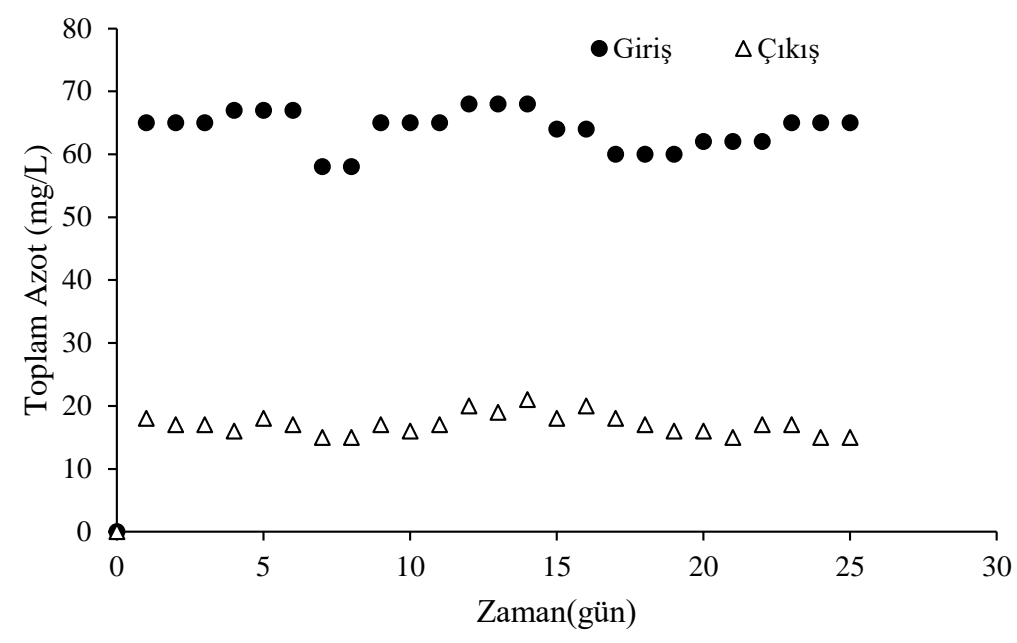

Şekil 3. Batık MBR sisteminde toplam azot konsantrasyonundaki değişimler Figure 3. Variation of total nitrogen concentrations in submerged MBR system

Su Kirliliği Kontrolü Yönetmeliği'nde, toplam azot konsantrasyonlarıla ilgili sınır değerler bulunmamaktadır (SKKY, 2008). Bununla birlikte, Kentsel Atıksu Arıtımı Yönetmeliği'nde ileri arıtma prosesleri çıkış sularında toplam azot konsantrasyonu için sınır değer $15 \mathrm{mg} / \mathrm{L}$ olarak belirtilmiştir (KAAY, 2006). Bu çalışmada elde edilen sonuçlar doğrultusunda arıtılmış gerçek gri suyun toplam azot konsantrasyonu en düşük $15 \mathrm{mg} / \mathrm{L}$ değerine kadar indirilebilmiştir. Bu değer yukarıda anılan sınır değere eşittir. Aynı zamanda bu çalışmada kullanılan batık MBR sisteminin ortalama çıkış toplam azot konsantrasyonu $17 \mathrm{mg} / \mathrm{L}$ olarak elde edilmiştir. Bu arıtılmış atıksu için söz konusu toplam azot konsantrasyonu gerekli deşarj sınır değerlerini karşılamamaktadır. Bu noktada, maksimum verim ve daha düşük toplam azot konsantrasyonlarının elde edilebilmesi için mevcut biyolojik arıtma sistemine anoksik arıtım prosesinin dâhil edilmesi zorunlu gözükmektedir. Ayrıca atıksuların geri kazanımı ve yeniden kullanımı ile ilgili bilgilerin yer aldığı tebliğde (AATTUT, 2010), geri kazanılmış suların sulama için faydalı olan besi maddelerini içerdiği ve bunun bitki büyümesini etkilediği belirtilmektedir. $\mathrm{Bu}$ açıdan, söz konusu tebliğde MBR ile sağlanabilecek geri kazanım neticesinde elde edilen atıksuda toplam azotun 7 ila $18 \mathrm{mg} / \mathrm{L}$ arasında olduğu belirtilmektedir. Bu çalışmada da ortalama toplam azot konsantrasyonu arıtılmış atıksuda $17 \mathrm{mg} / \mathrm{L}$ olarak belirlenmiştir.

\section{Toplam Fosfor Giderimi(Total Phosphorus Removal)}

Toplam azotla birlikte toplam fosfor parametresi alıcı ortamlarda ve biyolojik arıtma tesislerinde canlı halde olan tüm mikroorganizmalar için ana besin maddeleridir. Toplam fosfor, alıcı ortamlardaki ötrofikasyonu önlemek için etkili bir şekilde atıksulardan uzaklaştırılmalıdır. Gri suların aerobik arıtımında, toplam fosfor doğal olarak belli bir seviyeye kadar arıtılmaktadır. Fakat aynı zamanda, çıkış suyunda toplam fosforun azımsanmayacak bir miktarı kalabilmekte ve bu durum, alıcı su ortamlarına atıksu verilmeden önce daha ileri bir arıtımı gerekli kılabilmektedir.

$\mathrm{Bu}$ çalışmada, batık membran biyoreaktör ile gri suyun arıtımından önce ve sonra toplam fosfor konsantrasyonları izlenmiştir. Elde edilen sonuçlar Şekil 4'te gösterilmektedir.

Ham gerçek gri su örneklerindeki toplam fosfor konsantrasyonu 5,0-7,5 mg/L aralığında değişim gösterirken, arıtılmış çıkış suyunda ise bu değer aralığının 1,21-3,50 mg/L olduğu bulunmuştur. Ortalama olarak bu aerobik batık membran biyoreaktörün toplam fosfor giderim verimliliği ortalama \%64 olarak elde edilmiştir. Anaerobik ve anoksik safhaları bulunmayan bu aerobik arıtım prosesinin giderim verimliliği çok ta düşük gözükmemektedir. Fountoulakis ve diğ. 2016 tarafından gerçekleştirilmiş olan bir çalışmada, gri suyun arıtımı için düz levha şeklindeki bir membran modülü $(0,04 \mu \mathrm{m}$ gözenek boyutlu) kullanılmış olup, batık membran biyoreaktör sisteminden \%69'luk bir toplam fosfor giderim verimi elde edilmiştir (Fountoulakis ve di $\breve{g} ., 2016$ ). 


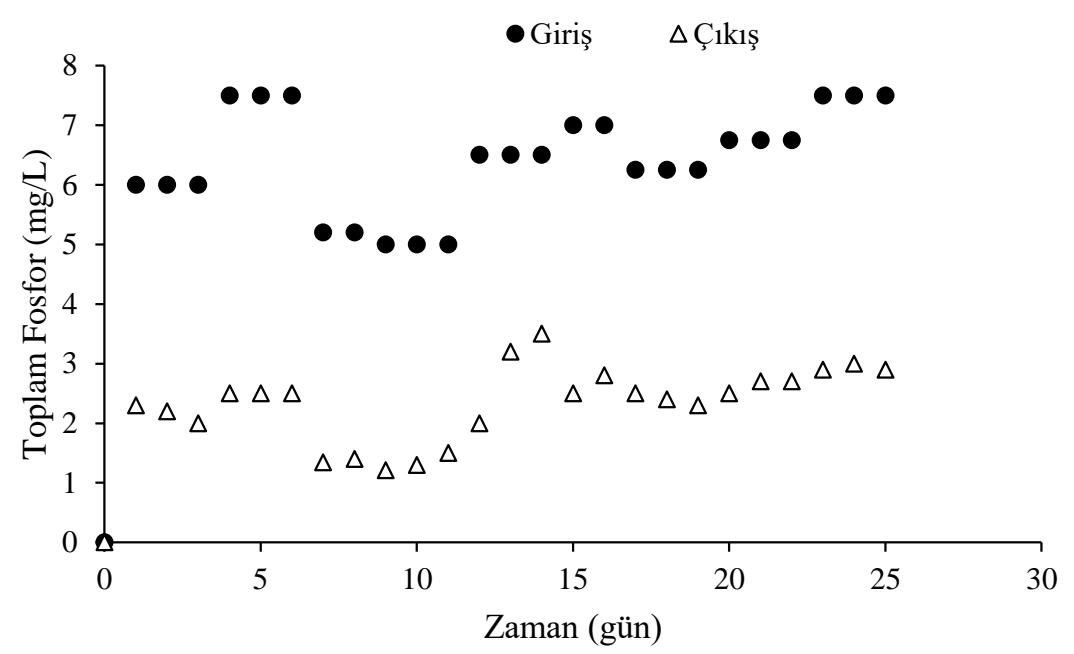

Şekil 4. Toplam fosfor konsantrasyonundaki değişim

Figure 4. Variation of total phosphorus concentration

Aerobik koşullar altındaki konvansiyonel bir reaktörde, acinetobacter isimli mikroorganizma aktif çamur karışık sıvısının oldukça önemli bir bölümünü oluşturmaktadır. Oran olarak ifade etmek gerekirse bu değer yaklaşık olarak \%40'ı bulmaktadır. Bu mikroorganizma anaerobik koşullar altında polihidroksibütirat (PHB) olarak adlandırılan depo polimerlerini oluşturmakta ve PHB'leri oluşturmak için gerekli olan enerjiyi sahip olduğu polifosfat granüllerini depolimerize ederek sağlamaktadır. Aerobik koşullar söz konusu olduğunda ise, bu mikroorganizma PHB ve diğer besi elementlerini karbon kaynağ 1 olarak kullanır ve bünyesine fosforu depolamaya başlar. Acinetobacter tarafından aerobik koşullarda depolanan fosfor miktarı, anaerobik koşullarda salınan fosforun iki katı olarak belirtilmektedir (Büyükgüngör, 2003). Dolayısıyla, bu durum membran destekli aktif çamur prosesinde toplam fosfor giderimine açıklık kazandırmaktadır.

Toplam fosfor konsantrasyonları için toplam azot deşarj standartlarının da belirlendiği Kentsel Atıksu Arıtımı Yönetmeliği hükümleri geçerlidir. Bu yönetmelik kapsamında, toplam fosfor için sınır konsantrasyon değeri $2 \mathrm{mg} / \mathrm{L}$ olarak belirlenmiştir (KAAY, 2006). Bu çalışmada kullanılan membran sistemi için elde edilen minimum toplam fosfor konsantrasyonu 1,21 mg/L iken, maksimum değer 3,50 $\mathrm{mg} / \mathrm{L}$ olarak bulunmuştur. Bu noktada, sistemden elde edilmiş olan ortalama fosfor konsantrasyonunun deşarj sınır değerlerinin üzerinde olduğu net bir şekilde görülebilmektedir. Fakat, bu membran biyoreaktör sisteminin çıkış suyu toplam fosfor değerleri deşarj standartlarına oldukça yakın olarak bulunmuştur. Ayrıca geri kazanım ile ilgili tebliğ (AATTUT, 2010) toplam fosfor açısından incelendiğinde, MBR sistemi ile elde edilebilecek arıtılmış sudaki toplam fosfor konsantrasyonlarının 0,3 ile $5 \mathrm{mg} / \mathrm{L}$ arasında olması gerektiği belirtilmektedir. Bu açıdan arıtılmış suda elde edilen ortalama fosfor konsantrasyonlarının bu aralıkta kaldığı net bir şekilde görülebilmektedir.

\section{SONUÇLAR(CONCLUSIONS)}

$\mathrm{Bu}$ çalışmada gerçek gri suların arıtımı için kullanılan bir batık membran biyoreaktörünün performansı incelenmiştir. KOİ, toplam azot ve toplam fosfor konsantrasyonları membran biyoreaktörün minimum, maksimum ve ortalama giderim verimliliklerini belirlemek için günlük olarak izlenmiştir. Bir evden temin edilen gerçek gri su, membran sistemi ile başarılı bir şekilde arıtılmış olup, ortalama olarak \%96 mertebesinde KOİ giderimi elde edilmiştir. Çıkış suyunda arta kalan KOİ konsantrasyonu, Türk Yasaları kapsamında belirlenmiş olan deşarj ve tekrar kullanım standartlarına göre kabul edilebilir bir değere sahiptir. Aynı zamanda, arıtılmış gri sudaki toplam azot ve toplam fosfor konsantrasyonları bu yasalar kapsamında söz konusu olan sınır değerlere oldukça yakın olarak 
bulunmuştur. Ayrıca ilgili tebliğlerde MBR sistemi kullanılarak geri kazanım neticesinde elde edilmesi beklenen arıtılmış atık sudaki toplam azot ve toplam fosfor konsantrasyon değerlerinin, bu çalışmada elde edilen sonuçlarla tutarlı olduğu görülmüştür. Batık membran biyoreaktörün arıtım verimlerinin aerobik bir biyolojik arıtma sistemine göre yüksek olmasına karşın, toplam azot ve toplam fosfor konsantrasyonlarının ortalama değerleri, grisu için deşarj yönetmelik değerlerinin yine de üzerinde yer almaktadır. Eğer atıksu deşarj edilecekse, yönetmelik değerlerinin tam olarak sağlanması, biyoreaktördeki aerobik koşullara ek olarak anoksik ve anaerobik şartları sağlayacak bir arıtım sistemiyle mümkün olabilecektir. Bunun haricinde atıksuyun geri kazanım neticesinde sulamada kullanılması amaçlanıyorsa, bu MBR sisteminin yeniden kullanım için organik madde, toplam azot ve toplam fosfor açısından gerekli arıtımı sağlamış olduğu sonucuna varılabilir.

\section{KATKI BELİRTME(ACKNOWLEDGEMENT)}

Yazarlar Ondokuz Mayıs Üniversitesi Çevre Mühendisliği Bölümüne sağlamış oldukları laboratuvar olanakları için teşekkür eder. Ayrıca bu çalışma Ondokuz Mayıs Üniversitesi tarafından PYO.MUH.1904.09.006 proje numarası ile desteklenmiştir.

\section{KAYNAKLAR(REFERENCES)}

AATTUT, 2010, Atıksu Arıtma Tesisleri Teknik Usuller Tebliği, Türkiye.

Abdel-Kader, A.M., 2013, "Studying the efficiency of grey water treatment by using rotating biological contactors system", Journal of King Saud University - Engineering Sciences, Cilt 25, ss. 89-95.

Al-Jayyousi, O.R., 2003, "Greywater reuse: towards sustainable water management", Desalination, Cilt 156, ss. 181-192.

APHA, 1985, Standart Methods for the Examination of Water and Wastewater, Sixteenth. ed. American Public Health Association, Washington, DC, ABD.

Arunbabu, V., Sruthy, S., Antony, I., Ramasamy, E.V., 2015, “Sustainable greywater management with axonopus compressus (broadleaf carpet grass) planted in sub surface flow constructed wetlands", Journal of Water Process Engineering, Cilt 7, ss. 153-160.

Bani-Melhem, K., Al-Qodah, Z., Al-Shannag, M., Qasaimeh, A., Rasool Qtaishat M., Alkasrawi, M., 2015, "On the performance of real grey water treatment using a submerged membrane bioreactor system", Journal of Membrane Science, Cilt 476, ss. 40-49.

Boddu, V.M., Paul, T., Page, M.A., Byl, C., Ward, L., Ruan, J., 2016, "Gray water recycle: effect of pretreatment technologies on low pressure reverse osmosis treatment", Journal of Environmental Chemical Engineering, Cilt 4, ss. 4435-4443.

Büyükgüngör, H., 2003, Atıksu Arıtma Yöntemleri, Ondokuz Mayıs Üniversitesi, Mühendislik Fakültesi, Çevre Mühendisliği Bölümü, Samsun, Türkiye.

CEC, 1991, Council Directive of 21 May 1991 Concerning Urban Waste Water Treatment (91/271/EEC).

Elmitwalli, T.A., Otterpohl, R., 2007, "Anaerobic biodegradability and treatment of grey water in upflow anaerobic sludge blanket (UASB) reactor", Water Research, Cilt 41, ss. 1379-1387.

Eriksson, E., Andersen, H.R., Madsen, T.S., Ledin, A., 2009, “Greywater pollution variability and loadings", Ecological Engineering, Cilt 35, ss. 661-669.

Fountoulakis, M.S., Markakis, N., Petousi, I., Manios, T., 2016, "Single house on-site grey water treatment using a submerged membrane bioreactor for toilet flushing", Science of the Total Environment, Cilt 551-552, ss. 706-711.

Friedler, E., Hadari, M., 2006, "Economic feasibility of on-site greywater reuse in multi-storey buildings", Desalination, Cilt 190, ss. 221-234.

Friedler, E., Katz, I., Dosoretz, C.G., 2008, “Chlorination and coagulation as pretreatments for greywater desalination", Desalination, Cilt 222, ss. 38-49.

Ghaitidak, D.M., Yadav, K.D., 2013, "Characteristics and treatment of greywater---A review", Environmental Science and Pollution Research, Cilt 20, ss. 2795-2809. 
Guo, W., Vigneswaran, S., Ngo, H.-H., Xing, W., Goteti, P., 2008, “Comparison of the performance of submerged membrane bioreactor (SMBR) and submerged membrane adsorption bioreactor (SMABR)", Bioresource Technology, Cilt 99, ss. 1012-1017.

Gürel, L., Büyükgüngör, H., 2011, “Treatment of slaughterhouse plant wastewater by using a membrane bioreactor", Water Science and Technology, Cilt 64, ss. 214-219.

Innocenti, L., Bolzonella, D., Pavan, P., Cecchi, F., 2002, “Effect of sludge age on the performance of a membrane bioreactor: Influence on nutrient and metals removal", Desalination, Cilt 146, ss. 467-474.

Judd, S., 2008, "The status of membrane bioreactor technology". Trends in Biotechnology, Cilt 26, ss. 109-116.

KAAY, 2006, Kentsel Atıksu Arıtımı Yönetmeliği, Türkiye.

Katukiza, A.Y., Ronteltap, M., Niwagaba, C.B., Kansiime, F., Lens, P.N.L., 2014, “Grey water treatment in urban slums by a filtration system: Optimisation of the filtration medium", Journal of Environmental Management, Cilt 146, ss. 131-141.

Kujawa-Roeleveld, K., Zeeman, G., 2006, “Anaerobic treatment in decentralised and source-separationbased sanitation concepts", Reviews in Environmental Science and Biotechnology, Cilt 5, ss. 115-139.

Li, F., Wichmann, K., Otterpohl, R., 2009, "Review of the technological approaches for grey water treatment and reuses", Science of the Total Environment, Cilt 407, ss. 3439-3449.

Liu, S., Butler, D., Memon, F.A., Makropoulos, C., Avery, L., Jefferson, B., 2010, “Impacts of residence time during storage on potential of water saving for grey water recycling system", Water Research, Cilt 44, ss. 267-277.

Lv, W., Zheng, X., Yang, M., Zhang, Y., Liu, Y., Liu, J., 2006, "Virus removal performance and mechanism of a submerged membrane bioreactor", Process Biochemistry, Cilt 41, ss. 299-304.

Ma, D., Chen, L., Liu, C., Bao, C., Liu, R., 2015, “Biological removal of antiandrogenic activity in gray wastewater and coking wastewater by membrane reactor process", Journal of Environmental Sciences (China), Cilt 33, ss. 195-202.

Melin, T., Jefferson, B., Bixio, D., Thoeye, C., De Wilde, W., De Koning, J., van der Graaf, J., Wintgens, T., 2006, "Membrane bioreactor technology for wastewater treatment and reuse", Desalination, Cilt 187, ss. 271-282.

Merz, C., Scheumann, R., El Hamouri, B., Kraume, M., 2007, “Membrane bioreactor technology for the treatment of greywater from a sports and leisure club", Desalination, Cilt 215, ss. 37-43.

Nawaz, T., Sengupta, S., 2017, "Silver recovery from greywater: Role of competing cations and regeneration", Separation and Purification Technology, Cilt 176, ss. 145-158.

Rosenberger, S., Krüger, U., Witzig, R., Manz, W., Szewzyk, U., Kraume, M., 2002, "Performance of a bioreactor with submerged membranes for aerobic treatment of municipal waste water", Water Research, Cilt 36, ss. 413-420.

Sanchez, M., Rivero, M.J., Ortiz, I., 2010, "Photocatalytic oxidation of grey water over titanium dioxide suspensions", Desalination, Cilt 262, ss. 141-146.

Santasmasas, C., Rovira, M., Clarens, F., Valderrama, C., 2013, “Grey water reclamation by decentralized MBR prototype", Resources, Conservation and Recycling, Cilt 72, ss. 102-107.

Scheumann, R., Kraume, M., 2009, "Influence of hydraulic retention time on the operation of a submerged membrane sequencing batch reactor (SM-SBR) for the treatment of greywater", Desalination, Cilt 246, ss. 444-451.

SKKY, (2008), Su Kirliligı̆ Kontrolü Yönetmeliğı̆, Türkiye.

Wurochekke, A.A., Harun, N.A., Mohamed, R.M.S.R., Kassim, A.H.B.M., 2014, “Constructed wetland of lepironia articulata for household greywater treatment", APCBEE Procedia, Cilt 10, ss. 103109.

Zuma, B.M., Tandlich, R., Whittington-Jones, K.J., Burgess, J.E., 2009, “Mulch tower treatment system part I: Overall performance in greywater treatment", Desalination, Cilt 242, ss. 38-56. 